\title{
Neisseria subflava
}

National Cancer Institute

\section{Source}

National Cancer Institute. Neisseria subflava. NCI Thesaurus. Code C86609.

A species of aerobic, Gram-negative, cocci shaped bacteria assigned to the phylum Proteobacteria. This species is catalase and oxidase positive, produces a yellowish pigment, non-hemolytic, utilizes glucose and maltose, but not mannose or lactose, reduces nitrite but not nitrate, and some strains spontaneously agglutinate in saline. $\mathrm{N}$. subflava is commensal in the human nasopharynx, but has been isolated in the cerebrospinal fluid of individuals with mening itis. 